\title{
INFLUENCE OF THE DENSITY OF PLACEMENT ON THE STABILITY OF ARMOUR LAYERS ON BREAKWATERS
}

\author{
Alwin VandenBosch ${ }^{1}$, Kees d'Angremond ${ }^{2}$, Henk Jan Verhagen ${ }^{3}$ and Jelle Olthof ${ }^{4}$
}

\begin{abstract}
Studies on the stability of the amour layer (d'Angremond et. al. [1999] revealed the importance of density of placement. The current research focuses on the influence of the density of placement on the stability of cubes in a double armour layer and tetrapods and rocks in a single armour layer. The experiments were performed in the Laboratory of Fluid Mechanics of the Faculty of Civil Engineering and Geosciences at the Technical University Delft. A model of a breakwater was constructed in a wave flume. An increase in density of placement resulted in all cases in an increase of stability, except in the case of cubes. Cubes have the tendency to start behaving like a placed block revetment including the characteristic failure mechanisms like uplift and sliding. Tetrapods seem to be unsuitable for single layer armour layers due to the fact that the filter layer is easily attacked by the waves even when no tetrapod has been removed. Experiments on rock showed that vertically placed elements lead to a much more stable construction due to their self-repairing ability. Characteristic for rock is the piling up of elements under the waterline caused by the impact of collapsing waves. This lead to very low densities of placement higher on the slope. Existing damage criteria are not suitable for density of placement. In this research an effort has been done to create a damage criteria, which considers area of attack, density of placement and different failure mechanisms.
\end{abstract}

\footnotetext{
${ }^{1}$ Graduate student, Delft University of Technology

${ }^{2}$ Professor, Delft University of Technology, Section of Hydraulic Engineering, P.O. Box 5048, NL2600GA Delft, The Netherlands, e-mail: K.dAngremond@ct.tudelft.nl

${ }^{3}$ Associate Professor, Delft University of Technology

${ }^{4}$ Senior Lecturer, Delft University of Technology
} 


\section{INTRODUCTION}

The objective of this study was to obtain insight in the influence of density of placement on the stability of cubes in a double armour layer and tetrapods and rock in a single armour layer. These elements were chosen because they are the most frequently used and in order to follow previous research. A few definitions have been used throughout this experiment:

- Start-of-damage is defined as the moment when the first element is removed.

- Failure takes place at the moment the filter layer is attacked.

- Density of placement is the number of elements per volume. This is varied in two different ways. In the case of cubes and tetrapods the density of placement was varied by varying the volumetric porosity. In case of rock the density of placement was varied by varying the layer thickness.

Previous investigations by d'Angremond (d'Angemond et. al. 1999) showed that a slope of 1:1.5 did not provide sufficient stability for rock in a single armour layer due to too much steepness. Therefore in this research shallower slopes were applied. Research by Hald, Tørum and Holm-Karlsen (Hald et. al. 1998) showed better results for stability in case of using orderly methods of placement. This was also applied in the current research. Furthermore in the research performed by d'Angremond tetrapods showed very unstable armour layers. This was due to the fact that d'Angremond used a very low density of placement. In the current research higher densities of placement were applied. Since the influence of density of placement for cubes in a single layer was already investigated by Van Gent et. al. [2000] in the current research cubes in a double layer have been investigated. Furthermore in case of rock the influence of slope and gradation in combination with density of placement was also be investigated.

During this study the observed failure mechanisms and the conditions in which they take place were investigated.

\section{EXPERIMENTS}

The experiments were performed in the Laboratory of Fluid Mechanics at the Faculty of Civil Engineering and Geosciences at the University of Technology Delft. In a waveflume a model of a breakwater was constructed. Picture 1 shows schematically one of the used breakwater models.

In front of the breakwater a concrete slope was constructed in the wave flume (1:30). At first the toe of the breakwater was made of the same material used for the filter layer. During the first experiments this turned out to be a too weak construction and it was decided to reinforce the toe by using rock used in the armour layer.

A JONSWAP-spectrum was used as energy-spectrum for the wave-field. The breakwater was exposed to a wave-series of 1000 waves with a specific significant wave-height. After a wave-series the significant wave-height was increased and the breakwater was exposed to the next wave-series. This process continued until the breakwater failed. Previous investigations (Van Gent et. al. 1998) showed no 


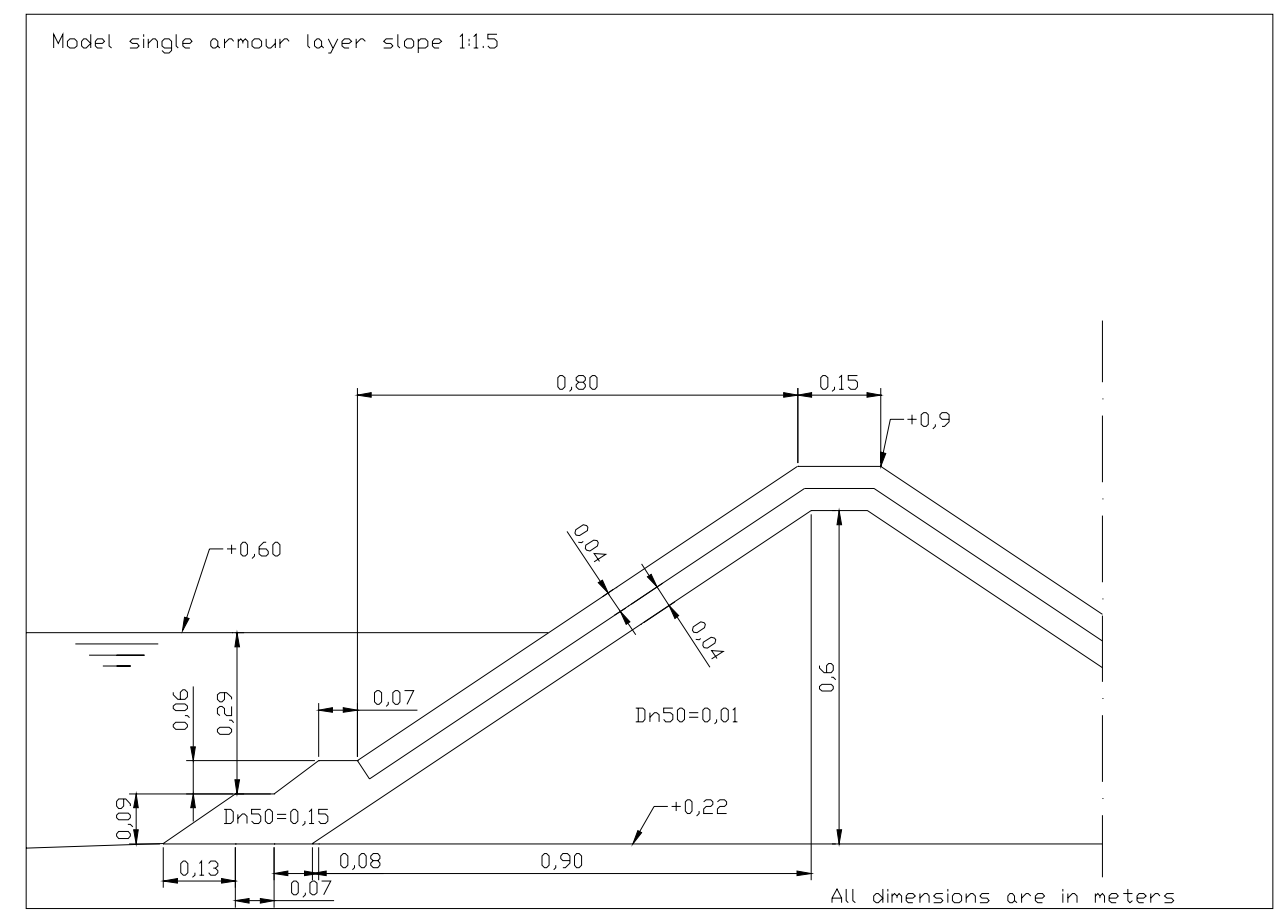

Figure 1: Crosssection breakwater model

influence of wave steepness on the stability of the armour layer. Therefore the wave steepness was held constant at 5\%.

The density of placement was varied in the case of cubes and tetrapods by varying the volumetric porosity of the armour layer. The density of placement of the rocks was varied by varying the layer thickness. A list of the performed experiments is shown in table 1. In this table A and B represent two special methods of placement besides the normal placement. The elements were placed vertically (method A) and horizontally (method B).

Table 1:Performed Experiments

\begin{tabular}{|c|c|c|c|}
\hline Element & Gradation & Volumetric porosity [-] & Slope \\
\hline Cube & - & $0.4 ; 0.3 ; 0.25$ & $1: 1.5$ \\
\hline Tetrapods & - & $0.4 ; 0.3 ; 0.25$ & $1: 1.5$ \\
\hline Rock & 1.2 & $0.3 ; \mathrm{A} ; \mathrm{B}$ & $1: 1.5 ; 1: 2 ; 1: 3$ \\
\hline Rock & 1.6 & 0.3 & $1: 2 ; 1: 3$ \\
\hline
\end{tabular}

\section{RESULTS}

\subsection{Cubes}

The first experiments were performed with the original weaker toe. This resulted in the removal of many elements in the lower regions of the breakwater due to weaknesses in the toe. Eventually this led to the complete sliding down of the upper armour layer, while the lower armour layer did not suffer any damage at all. The lower armour layer was rearranged into some sort of placed block revetment. To reduce the negative effect of the toe it was decided to reinforce it. 
The experiments were repeated with a reinforced toe and the results of these experiments are shown in figure 2. In this graph $\mathrm{N}_{\mathrm{od}}$ is the number of removed elements per width $D_{n}$ over the armour layer. $D_{n}$ is the nominal diameter. $H_{s} /\left(\Delta D_{n}\right)$ is a damage number in which $H_{s}$ is the significant wave height and $\Delta$ is the relative density.

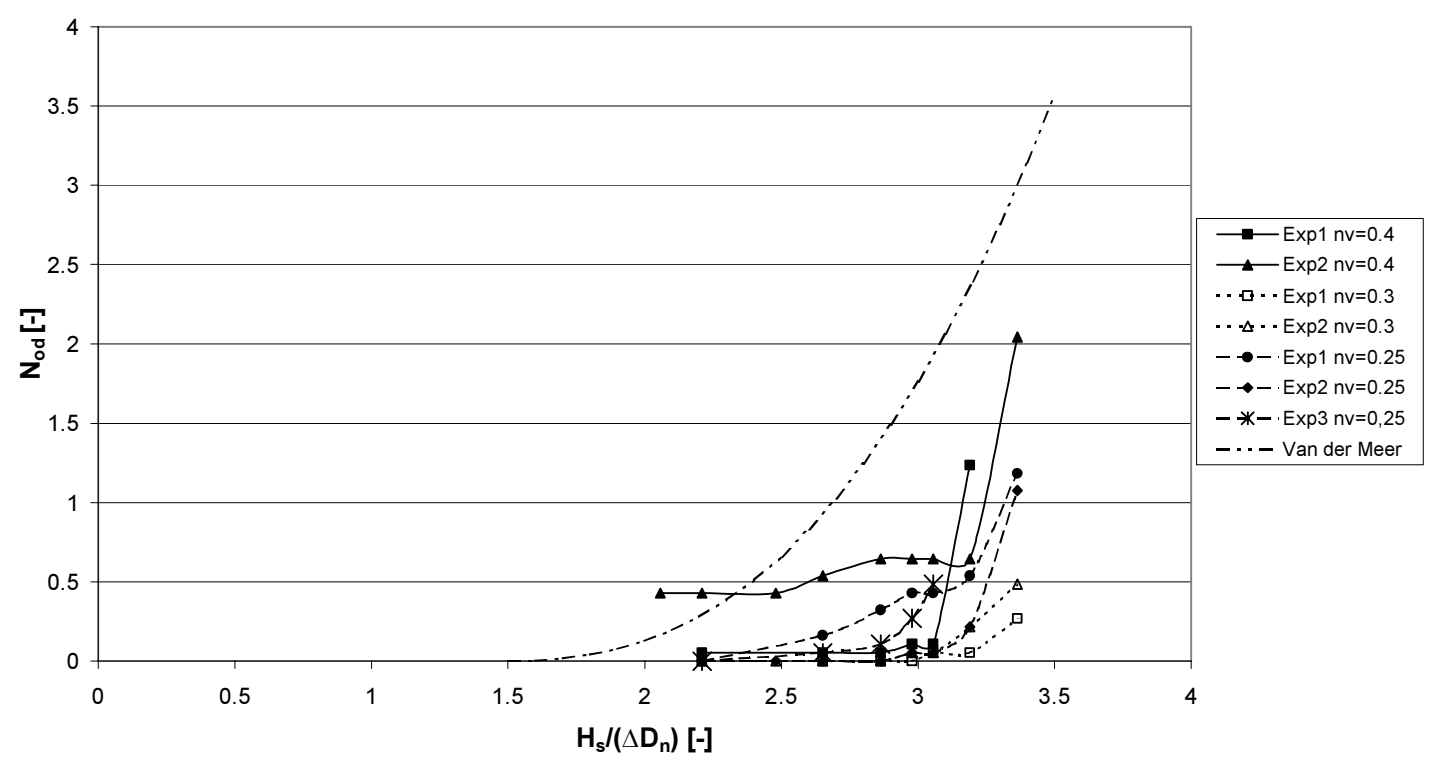

Figure 2: Damage development cubes

As the density of placement increased different failure mechanisms were observed. Uplifting and sliding started to dominate as failure mechanisms. Uplifting took place at the location of maximum wave setdown. As expected a volumetric porosity of 0.4 resulted to be the weakest construction. A volumetric porosity of 0.3 showed an increase in strength, however, a further increase of density of placement caused a reduction in strength. This can be explained by the fact that the armour layer started to resemble a placed block revetment with its typical failure mechanisms uplifting and sliding. Also shown in figure 2 is the damage development according to the theory of Van der Meer for an 'ordinary' density of placement, which is around 0.5. As expected this shows a weaker armour layer.

The stability of one element in the armour layer regarding uplift has been calculated using the method of Wolsink-Banach, which is used for placed block revetments (Bezuijen et. al. 1990). The calculation is done for a volumetric porosity of 0.3 and 0.25 and for a hypothetical breakwater with a volumetric porosity of 0.25 . The results are shown in figure 3. In this graph the ratio R/S stands for strength/load. The graphs show a decrease of the stability of the cube in case of an increase of density of placement. This is caused by the increase of leakage length, which causes an increase in the maximum head difference. The prototype is far less stable than the scale model. This is caused by the fact that the maximum head difference is relatively larger in case of the prototype. The reason for this is the method used to scale the elements. Therefore conclusions concerning stability versus uplift between the scalemodel and the prototype can not be drawn using these results. 
Another phenomenom characteristic for placed block revetments is clamping, which increases the strength of the individual elements. A calculation has been performed for this phenomenon and resulted in such an increase of stability that failure seemed to be completely out of the question. One can only conclude from these results that the calculation has not been performed correctly. It might be possible that the armour layer still does not resemble enough a placed block revetment to allow the application of the used calculation methods.

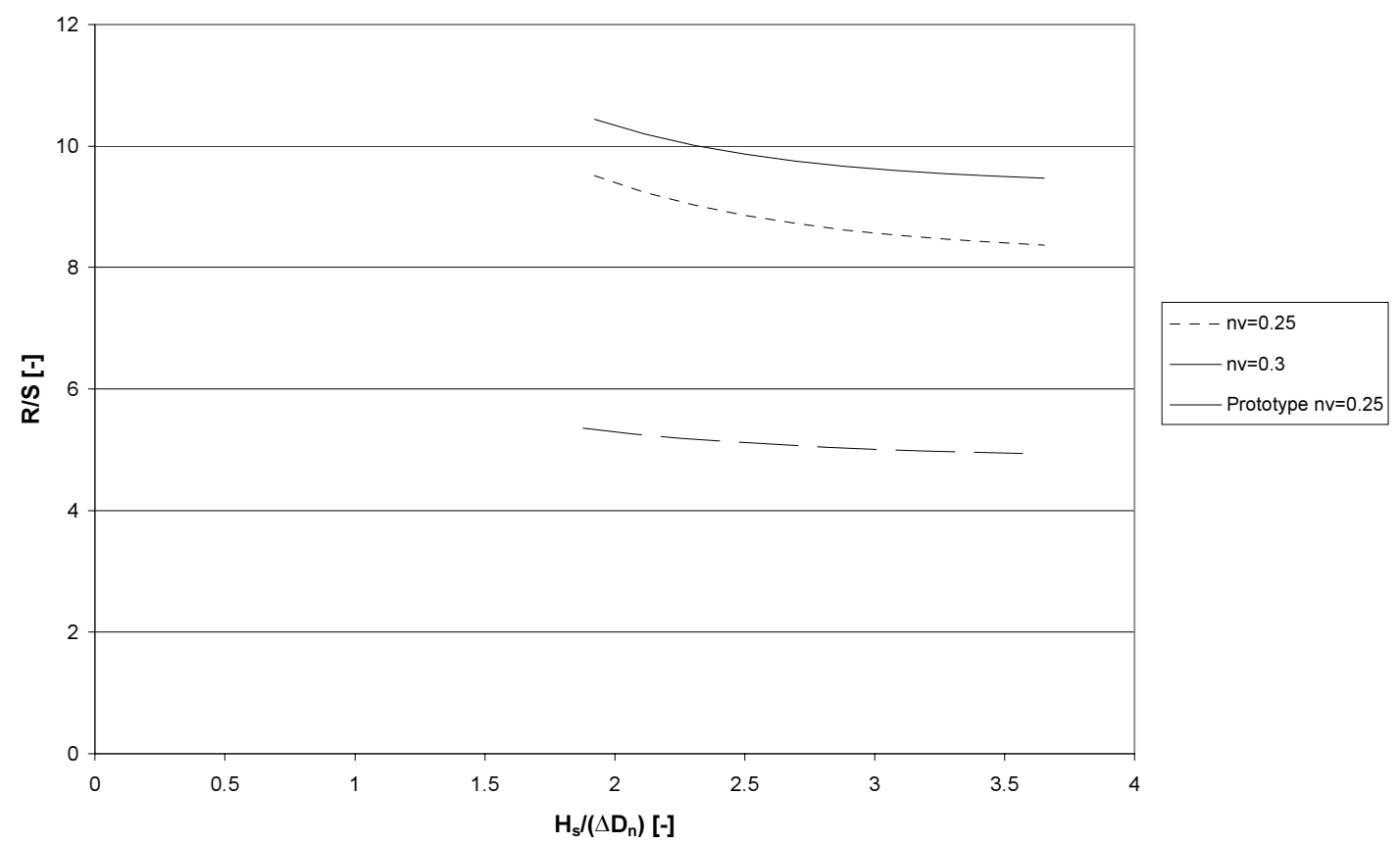

Figure 3: Comparison experiments with hypothetical breakwater with regards to uplift

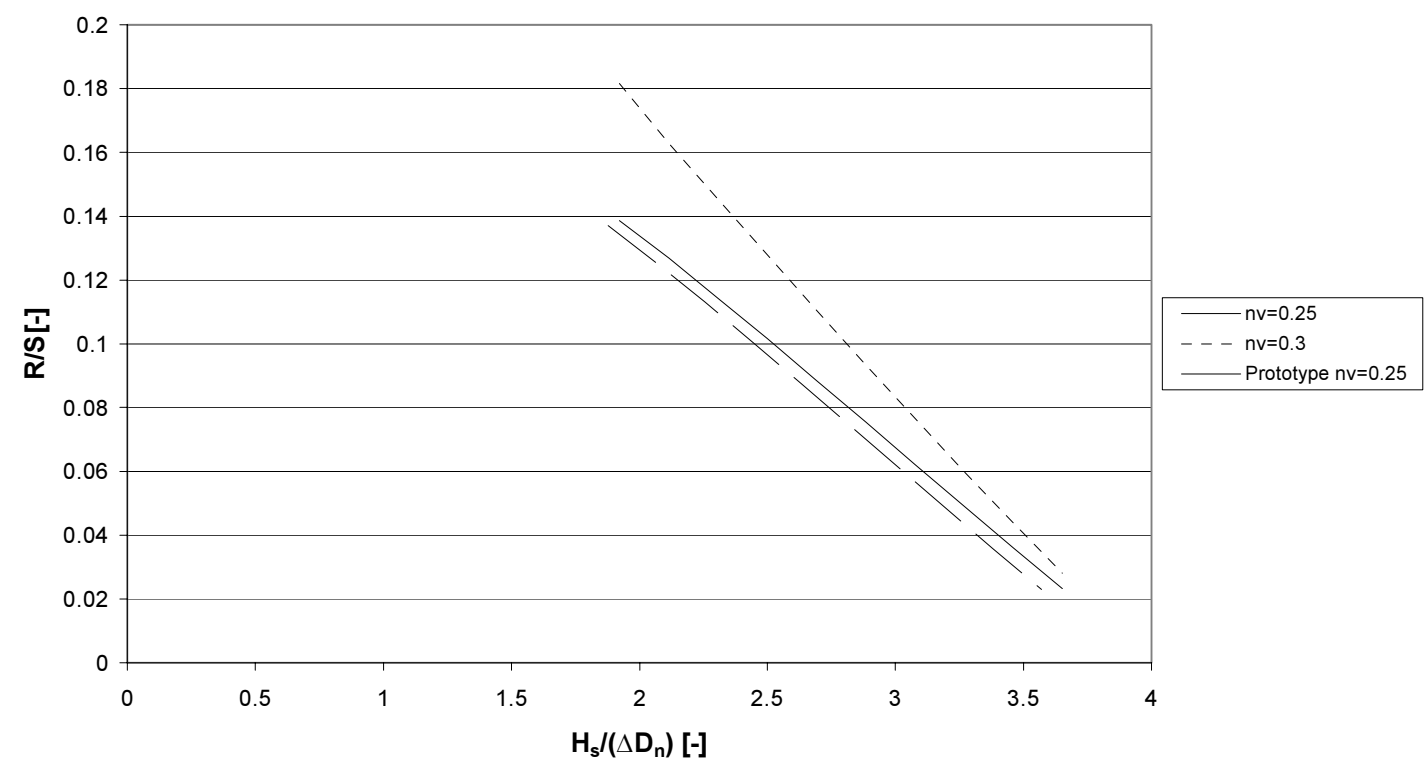

Figure 4: Comparison experiments with hypothetical breakwater with regards to sliding

Using a calculation method developed by Wolsink Banach (Bezuijen et. al. 1990) the stability of one element versus sliding was calculated. Once again the same 
calculation was done for a hypothetical breakwater with a volumetric porosity of 0.25 . Figure 4 shows the results of the calculation. Increase of density of placement causes a reduction of stability. The graph of the prototype very much resembles the graph of the scalemodel.

\subsection{Tetrapods}

The experiments with tetrapods were all performed with the reinforced toe. Uplift and sliding did not take place in the case of tetrapods. This was due to the fact that tetrapods never started resembling a placed block revetment, because of their particular form. However, a lot of rearranging of the elements took place. In such fashion that very few elements needed to be removed for failure to take place.

Another remarkable aspect of tetrapods was the fact that the filter layer was attacked by the waves already before one element was removed. This was possible because of the large spaces between the elements. Hollow spaces were created around the waterline where filter material was removed, which undermined the armour layer. The hole in the armour layer, which caused failure of the breakwater appeared much higher on the slope due to rearrangement of the elements. The results of the experiments are shown in figure 5.

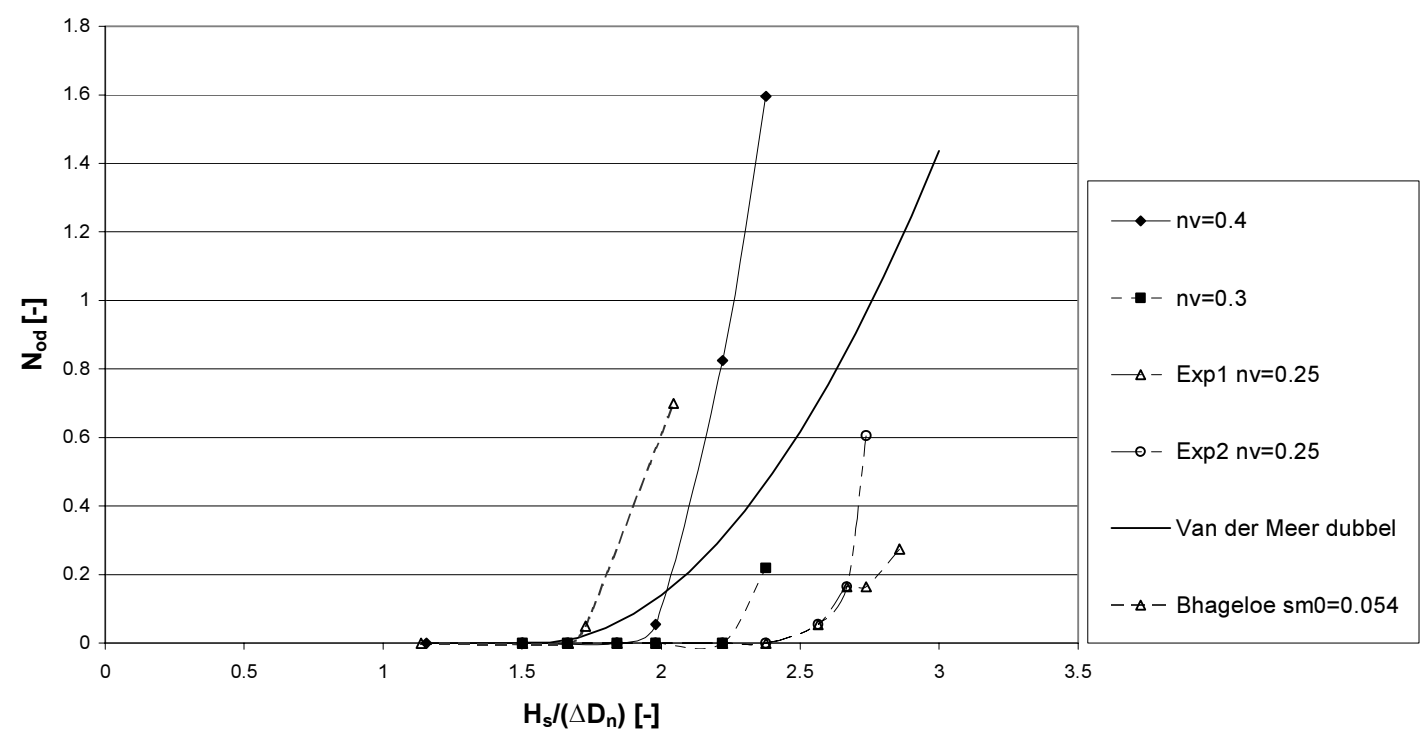

Figure 5: Damage development tetrapods

Stability of the armour layer increases with an increase of the density of placement. The figure also shows the results of the experiments of d'Angremond, who used a volumetric porosity of 0.62 . This results in a weaker armour layer. Also plotted in the graph is the damage development according to the theory of Van der Meer for a double armour layer.

Tetrapods obtain their stability from interlocking between the elements. The stability of one element in the armour layer was calculated using Hattori's calculation method (Hattori et. al. 2000). Since many variables used in this calculation were not measured during these experiments assumptions have been made resulting in a 
calculation for a high and a low density of placement. The results can only be used to distinguish a trend. The results are shown in figure 6.

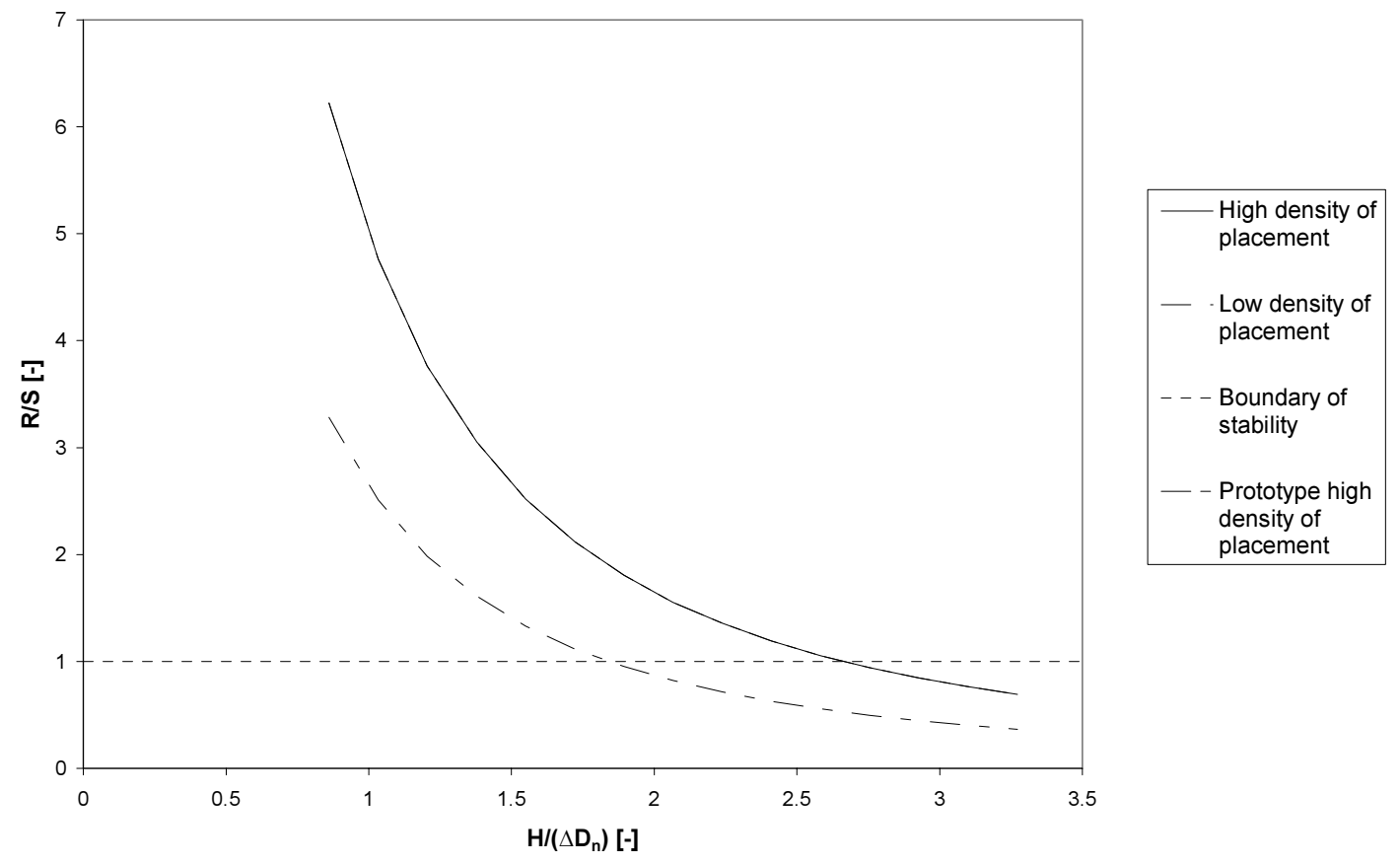

Figure 6: Ratio strength/load vs damage number

The graph for the prototype is exactly the same as the graph for the scale model. It is clearly visible that an increase in density of placement results in a higher stability.

\subsection{Rock}

Damage in the case of rock took place around the waterline. The gap in the armour layer causing failure appeared much higher on the slope due to rearranging of the elements. As mentioned before three methods of placement were applied: normal placement, method A (vertical placement) and method B (horizontal placement). Progressive failure was visible in case of slopes 1:1.5 and 1.2. This was no longer the case for slope 1:3. Collapsing waves caused most damage and these no longer took place in case of a slope 1:3. Instead plunging waves increased in quantity and these obviously caused less damage. Collapsing waves caused the piling up of elements in the lower regions. Elements in the lower surfaces reached a huge density of placement, while the higher surfaces reached a very low density. Figure 7, 8 and 9 show the results of the experiments.

Method of placement A shows the best results. This is due to its self-repairing ability. Once some elements are removed other elements reposition themselves in such a fashion that they cover the filter layer completely. Method of placement B lacks this ability and shows the worst results. The results of the wide gradation show that once a weak point in the armour layer is created all the small elements were 
removed easily. Hereafter the other elements quickly lost their stability. Obviously shallower slopes give better results for stability.

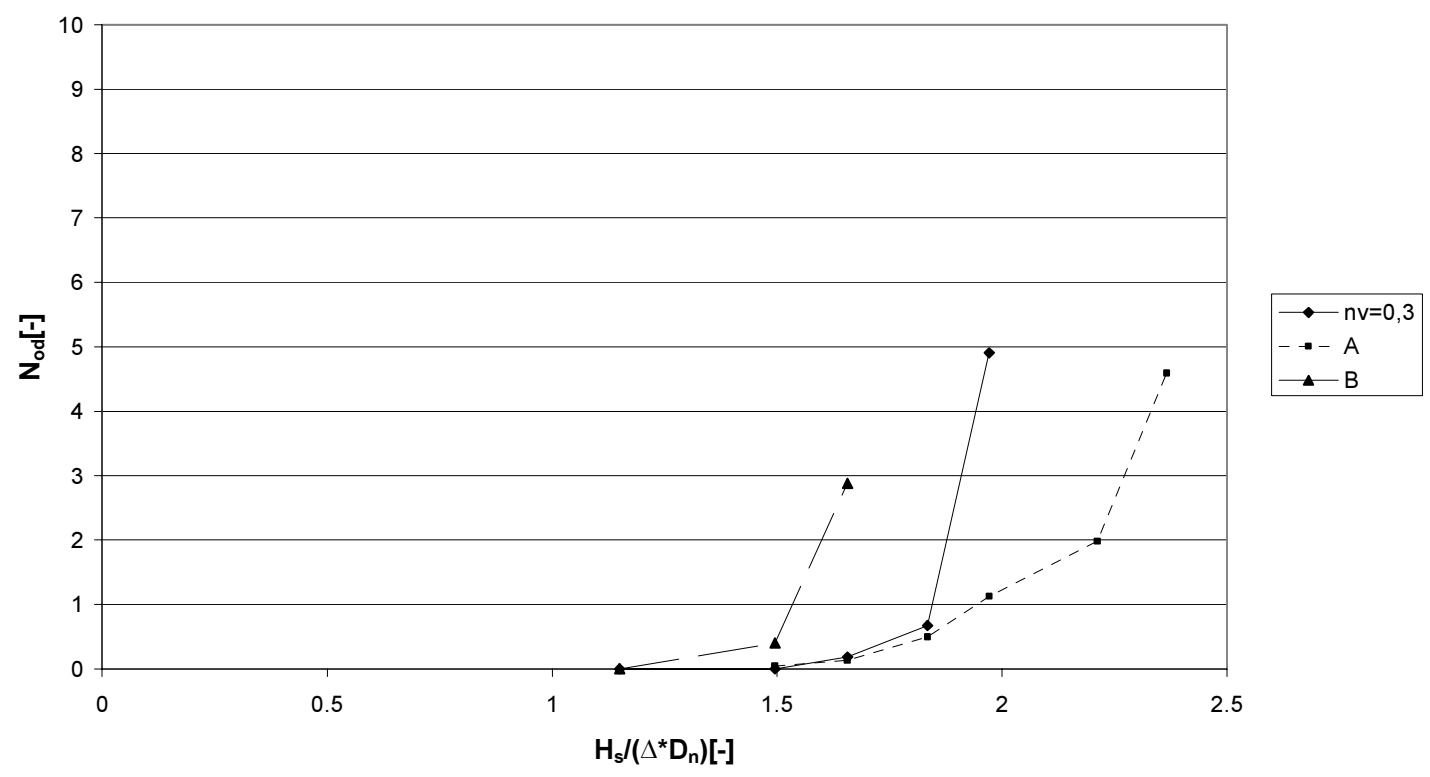

Figure 7: Damage development rock 1:1.5

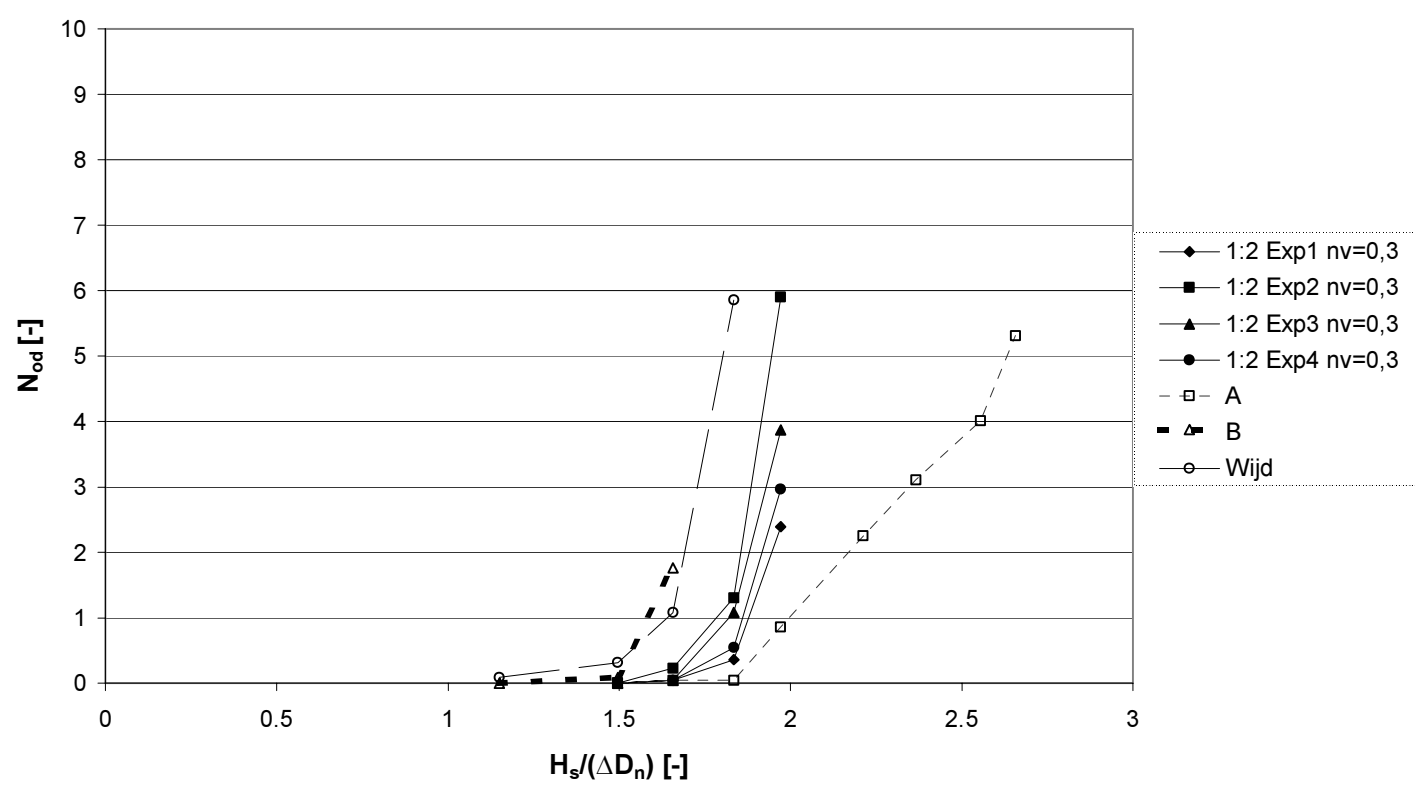

Figure 8: Damage development rock 1:2 


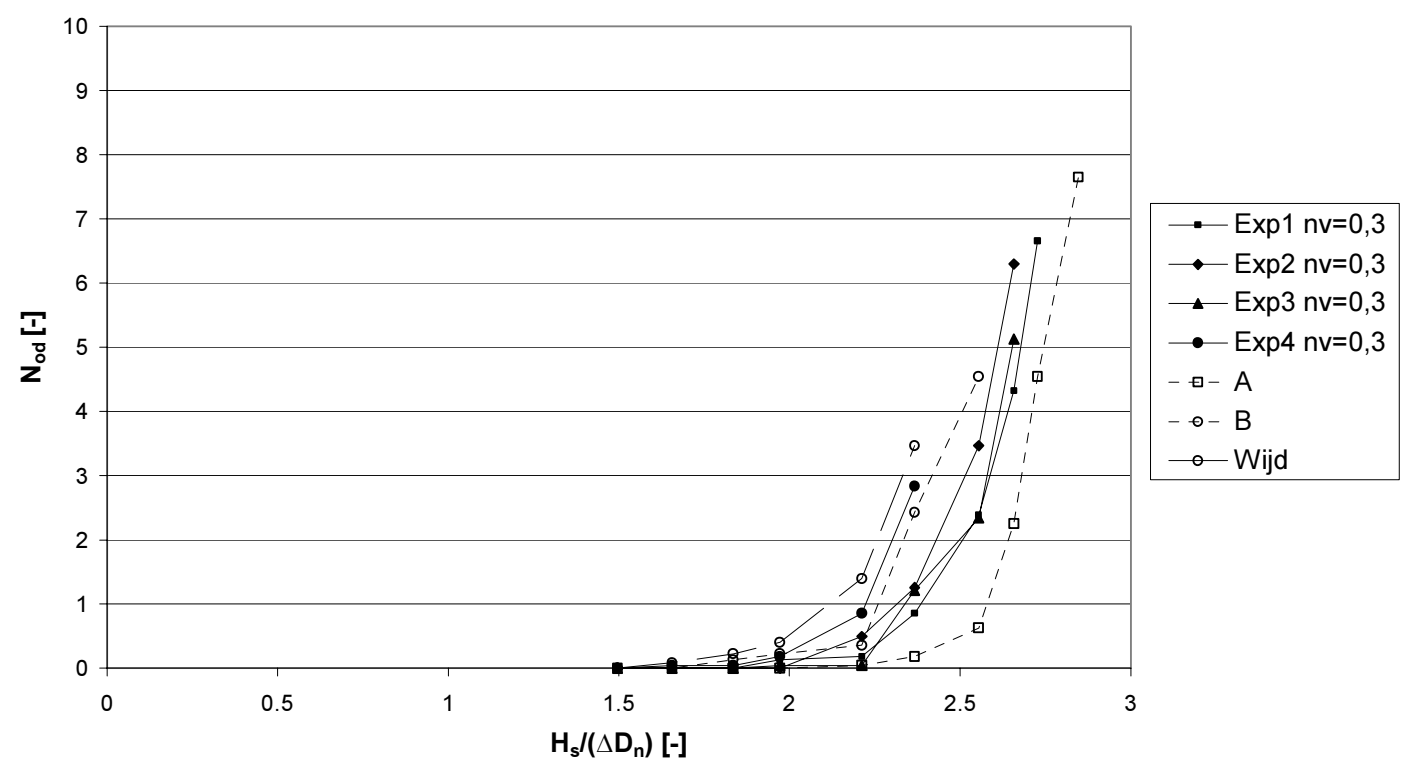

Figure 9: Damage development rock 1:3

\section{DAMAGE CRITERIA}

The use of $\mathrm{N}_{\text {od }}$ is unclear in case of varying densities of placement. The removal of for example 5 elements in case of a low density is far worse than in case of a high density. Another remark that can be made is the fact that $\mathrm{N}_{\mathrm{od}}$ does not take into account the size of the attacked surface. Furthermore one can distinguish different forms of damage each with their own specific value of importance.

An option is to relate the area of attack to the significant wave height. This sounds reasonable since a higher wave will attack a larger surface. A possibility for defining the area of attack is shown in figure 10.

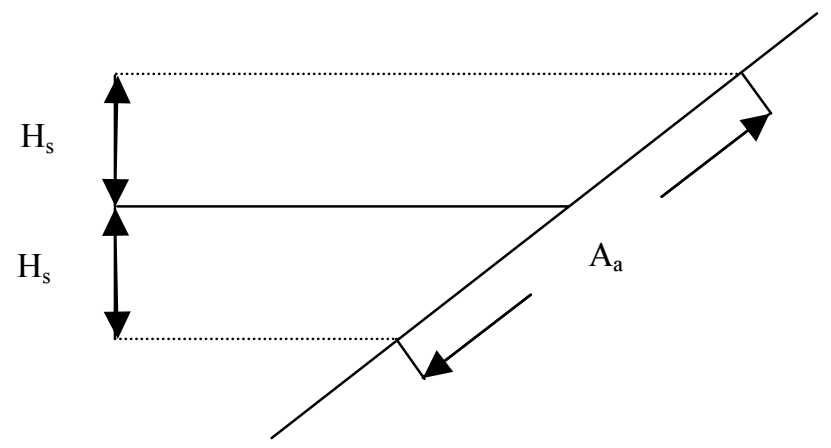

Figure 10: Area of attack

$A_{a}$ in the picture is the area of attack. If this definition is maintained the area of attack can be described in the following way.

$$
A_{a}=B \frac{2 H_{s}}{\sin \alpha}
$$

Where $B$ is the width of the area, $\alpha$ is the slope angle and $H_{s}$ is the significant wave height. The density of placement can be introduced in the following way: 


$$
N_{a}=\frac{\left(1-n_{v}\right)}{D_{n}^{2}}
$$

Where $N_{a}$ is the density of placement, $n_{v}$ is the volumetric porosity and $D_{n}$ is the nominal diameter of an element. The quantity of attacked elements in the area of attack now equals:

$$
N=A_{a} N_{a}
$$

The new damage number $\mathrm{N}_{\text {on }}$ can now be defined as:

$$
N_{o n}=\frac{N_{o}}{N}=\frac{N_{o} D_{n}^{2} \sin \alpha}{2 H_{s} B\left(1-n_{v}\right)}
$$

This new damage number is related to the significant wave height and the density of placement of the armour layer. An increase of density of placement results in a lower value of $\mathrm{N}_{\text {on }}$. This means that the same amount of damage results in a lower damage number. This sounds reasonable since the same amount of damage has less significance to an armour layer with a high density of placement than in case of a low density of placement.

This research showed three different forms of damage:

- $\mathrm{N}_{\mathrm{od}}=$ removed elements

- $\mathrm{N}_{\mathrm{or}}=$ rocking elements

- $\mathrm{N}_{\mathrm{os}}=$ moved elements (due to sliding)

The importance of each damage form differs. $\mathrm{N}_{\text {od }}$ is the heaviest form of damage. $\mathrm{N}_{\mathrm{os}}$ is of less importance. Elements removed due to sliding do not necessarily leave a gap in the armour layer of the same size as the element itself. Due to a constant process of repositioning this gap is reduced in size. The importance of $\mathrm{N}_{\text {or }}$ varies for each element. One can imagine it to be more important in case of slender elements as tetrapods, since rocking can lead to rupture, while it is insignificant in case of rock. Therefore each form of damage must be multiplied by a coefficient. If implemented in the damage formula this gives the following equation.

$$
N_{o n}=\frac{\left(a N_{o d}+b N_{o s}+c N_{o r}\right) D_{n}^{2} \sin \alpha}{2 H_{s} B\left(1-n_{v}\right)}
$$

The parameters $\mathrm{a}, \mathrm{b}$ and $\mathrm{c}$ in this equation are the coefficients used to determine the value of each form of damage.

\section{CONCLUSIONS AND RECOMMENDATIONS}

\subsection{Cubes}

Raising of the density of placement with cubes leads to more stable constructions. In table 2 the results of the experiments with a reinforced toe are shown. 
Table 2: Indication for 'start-of-damage' and failure for cubes

\begin{tabular}{|c|c|c|c|c|}
\hline \multirow{2}{*}{$\mathbf{n}_{\mathbf{v}}$} & \multicolumn{2}{|c|}{ 'Start-of-damage' } & \multicolumn{2}{c|}{ Failure } \\
\cline { 2 - 5 } & $\mathbf{H}_{\mathbf{s}} /\left(\Delta \mathbf{D}_{\mathbf{n}}\right)[-]$ & $\mathbf{N}_{\mathbf{o d}}[-]$ & $\mathbf{H}_{\mathbf{s}} /\left(\Delta \mathbf{D}_{\mathbf{n}}\right)[-]$ & $\mathbf{N}_{\mathbf{o d}}[-]$ \\
\hline 0.4 & 2.47 & 0.055 & 3.3 & 2 \\
\hline 0.3 & $2.98-3.07$ & 0.055 & - & - \\
\hline 0.25 & $2.32-3.05$ & 0.055 & - & - \\
\hline
\end{tabular}

A trend can be seen that a higher density of placement leads to a more stable construction. Remarkable is the fact that a density of placement of 0.25 leads to a less stable construction. This is due to the fact that the armour layer starts behaving like a placed block revetment. Characteristic failure mechanism is rocking, which eventually leads to the removal of the element. This took place around the waterline. In case of high densities of placement uplifting and sliding start to take place as failure mechanisms.

For uplifting calculations with the method of Wolsink Banach seem to show that the stability is less in case of the prototype than in case of the scale model. This can be related to the method of scaling used to determine the size of the elements in the prototype. Conclusions can not be drawn from these results. Sliding starts to become more important in case of higher densities of placement. This is because the roughness between the upper and lower armour layer decreases. Calculations show that this failure mechanism is similar in case of the scale model and the prototype.

To determine clear criteria for 'start-of-damage' and failure more experiments must be performed. Concerning the failure mechanisms calculations have been made in which many assumptions had to be made since these variables were not measured during the experiments. These variables must be investigated to allow better calculations.

\subsection{Tetrapods}

Armour layers made of tetrapods acquire better stability results with the increase of density of placement. Table 3 shows the results for the experiments with tetrapods.

Table 3: Indication for 'start-of-damage' and failure for tetrapods

\begin{tabular}{|c|c|c|c|c|}
\hline \multirow{2}{*}{$\mathbf{n}_{\mathbf{v}}$} & \multicolumn{2}{|c|}{ 'Start-of-damage' } & \multicolumn{2}{c|}{ Failure } \\
\cline { 2 - 5 } & $\mathbf{H}_{\mathbf{s}} /\left(\Delta \mathbf{D}_{\mathbf{n}}\right)[-]$ & $\mathbf{N}_{\mathbf{o d}}[-]$ & $\mathbf{H}_{\mathbf{s}} /\left(\Delta \mathbf{D}_{\mathbf{n}}\right)[-]$ & $\mathbf{N}_{\mathbf{~ o d}}[-]$ \\
\hline 0.4 & 2.00 & 0.054 & - & - \\
\hline 0.3 & 2.26 & 0.054 & 2.4 & 0.22 \\
\hline 0.25 & 2.57 & 0.054 & $2.74-2.86$ & $0.28-0.61$ \\
\hline
\end{tabular}

The values found for 'Start-of-damage' are remarkably higher than values found in previous investigations for double armour layers confirming the significance of density of placement. Low densities of placement are characterised by progressive failure. The characteristic failure mechanism is the same as in the case of cubes, rocking which eventually leads to the removal of the element. Another failure 
mechanism noticed in the case of tetrapods is the removal of filter material while only a small rearrangement of the elements has taken place. Due to the shape of the tetrapods there is so much space available between the elements that the waves can attack the filter almost immediately causing the material to be washed out. The removal of filter material started just above the waterline causing a hollow space under the armour layer. Furthermore many rearrangements of the armour layer took place while none or few elements had been removed eventually leading to cracks in the armour layer. Therefore tetrapods do not seem suitable for the use in single armour layers.

Tetrapods obtain their stability from interlocking. A calculation method developed by Hattori was used to determine the stability of one single element. The calculation confirmed the fact that an increase in density of placement results in an increase of stability.

As recommendations the same remarks apply as in case of the cubes. More repetitive experiments are necessary to obtain better results and the assumptions used in the calculation method of Hattori must be investigated.

\subsection{Rock}

As for rock the results of the experiments are presented in table 4.

Table 4: Indication for 'start-of-damage' and failure for tetrapods

\begin{tabular}{|c|c|c|c|c|c|}
\hline \multirow{2}{*}{$\begin{array}{l}\text { Method of } \\
\text { placement }\end{array}$} & \multirow{2}{*}{ Slope } & \multicolumn{2}{|c|}{ 'Start-of-damage' } & \multicolumn{2}{c|}{ Failure } \\
\cline { 3 - 6 } & & $\mathbf{H}_{\mathbf{s}} /\left(\Delta \mathbf{D}_{\mathbf{n}}\right)[-]$ & $\mathbf{N}_{\mathbf{~ o d}}[-]$ & $\mathbf{H}_{\mathbf{s}} /\left(\Delta \mathbf{D}_{\mathbf{n}}\right)[-]$ & $\mathbf{N}_{\text {od }}[-]$ \\
\hline Normal & $1: 1.5$ & 1.57 & 0.045 & 1.97 & 4.91 \\
\hline A & $1: 1.5$ & 1.47 & 0.045 & 2.54 & 4.59 \\
\hline B & $1: 1.5$ & 1.33 & 0.045 & 1.66 & 2.88 \\
\hline Normal & $1: 2$ & $1.51-1.67$ & 0.045 & $1.83-1.97$ & $1.31-3.87$ \\
\hline A & $1: 2$ & 1.64 & 0.045 & 2.66 & 5.31 \\
\hline B & $1: 2$ & 1.46 & 0.045 & 1.66 & 1.76 \\
\hline Wide gradation & $1: 2$ & 1.10 & 0.045 & 1.84 & 5.85 \\
\hline Normal & $1: 3$ & $1.73-2.02$ & 0.045 & $2.37-2.73$ & $2.84-6.66$ \\
\hline A & $1: 3$ & 2.24 & 0.045 & 2.85 & 7.65 \\
\hline B & $1: 3$ & 1.75 & 0.045 & 2.37 & 2.43 \\
\hline Wide gradation & $1: 3$ & 1.56 & 0.045 & 2.37 & 3.47 \\
\hline
\end{tabular}

An increase in density of placement results in an increase of stability. Method of placement A, where all the elements are placed vertically showed the best results due to its self-repairing ability. Characteristic failure mechanism was the piling up of elements in the lower surfaces of the armour layer due to the impact of collapsing waves causing very low densities of placement higher on the slope.

Stability increased in case of shallower slopes due to the decrease of collapsing waves and the increase of plunging waves. Method of placement B and the normal method of placement showed progressive failure in case of slopes 1:1.5 and 1.2. Furthermore narrower gradations show better stability results. 
A recommendation for rock is the performance of more repetitive experiments to obtain more results and to allow better values for 'start-of-damage' and failure.

\subsection{General}

A few general recommendations can be made. First of all an investigation is necessary into the possibilities of realising these densities of placement in practice. Is it possible to build such an armour layer from a technical and a financial point of view.

Further investigation into the new damage criteria is required, especially into the relation between the significant wave height and the area of attack and into the coefficients used for the various damage forms.

\section{ACKNOWLEDGEMENTS}

This work was supported by Royal Boskalis Westminster Dredging Company, Papendrecht, Netherlands. The tests were funded by and conducted in the Laboratory of Fluid Mechanics of the Delft University of Technology. Materials used during the experiments were provided by Delft Hydraulics.

\section{REFERENCES}

Angremond, K. d', E. Berendsen, G.S. Bhageloe, M.R.A. van Gent, J.W. van der Meer, (1999) Breakwaters with a single armour layer. Fifth International Conference on Coastal and Port Engineering in Developing Countries, p. 14411449, Council for Scientific and Industrial Research, Capetown, South Africa.

Bezuijen, A., e.a. (1990) Taludbekleding van gezette steen; samenvatting van onderzoeksresultaten 1980-1988. Dienst Weg- en Waterbouwkunde van Rijkswaterstaat, Delft, The Netherlands.

Gent, M.R.A. van, e.a. (1999) Single layer rubble mound breakwaters. Proceedings of the International Conference on Coastal Structures, p. 231-239, Santander, Spain.

Gent, M.R.A. van, C. Kuiper (2000) Single layer rubble mound breakwaters with high-density concrete cubes H3657. Delft Hydraulics, Delft, The Netherlands.

Hald, T., A. Tørum, T. Holm-Karlsen, (1998) Design of rock armoured single layer rubble mound breakwaters. Proceedings of the International Conference on Coastal Engineering, Sidney 1998, p 1800-1813.

Hattori, Masatoro, Eiji Yauchi, Yasutaka Kasahara, (1999) Hydraulic stability of armor units in single cover layer. Proceedings of the International Conference Coastal Structures, pag. 241-248, Santander, Spain. 